\title{
Anti-Influenza with Green Tea Catechins: A Systematic Review and Meta-Analysis
}

\author{
Anchalee Rawangkan ${ }^{1,2} \mathbb{D}$, Kirati Kengkla ${ }^{3,4,5}$, Sukrit Kanchanasurakit ${ }^{3,4,5,6} \mathbb{D}$, Acharaporn Duangjai ${ }^{1,2,4}$ \\ and Surasak Saokaew $2,3,4,5,6,7,8, *$ (D)
}

1 School of Medical Sciences, University of Phayao, Phayao 56000, Thailand; ewmedsci@gmail.com (A.R.); achara.phso@gmail.com (A.D.)

2 Unit of Excellence on Clinical Outcomes Research and IntegratioN (UNICORN), School of Pharmaceutical Sciences, University of Phayao, Phayao 56000, Thailand

3 Division of Pharmacy Practice, Department of Pharmaceutical Care, School of Pharmaceutical Sciences, University of Phayao, Phayao 56000, Thailand; kirati.ke@gmail.com (K.K.); sukrit.ka@up.ac.th (S.K.)

4 Center of Health Outcomes Research and Therapeutic Safety (Cohorts), School of Pharmaceutical Sciences, University of Phayao, Phayao 56000, Thailand

5 Unit of Excellence on Herbal Medicine, School of Pharmaceutical Sciences, University of Phayao, Phayao 56000, Thailand

6 Division of Pharmaceutical Care, Department of Pharmacy, Phrae Hospital, Phrae 54000, Thailand

7 Biofunctional Molecule Exploratory Research Group, Biomedicine Research Advancement Centre, School of Pharmacy, Monash University Malaysia, Bandar Sunway, Selangor Darul Ehsan 47500, Malaysia

8 Novel Bacteria and Drug Discovery Research Group, Microbiome and Bioresource Research Strength, Jeffrey Cheah School of Medicine and Health Sciences, Monash University Malaysia, Bandar Sunway, Selangor Darul Ehsan 47500, Malaysia

* Correspondence: surasak.sa@up.ac.th; Tel.: +66 (0)5446 6666; Fax: +66 (0)5446 6661

Citation: Rawangkan, A.; Kengkla, K.; Kanchanasurakit, S.; Duangjai, A.; Saokaew, S. Anti-Influenza with Green Tea Catechins: A Systematic Review and Meta-Analysis. Molecules 2021, 26, 4014. https://doi.org/ $10.3390 /$ molecules26134014

Academic Editor: Raphaël E. Duval

Received: 13 June 2021

Accepted: 29 June 2021

Published: 30 June 2021

Publisher's Note: MDPI stays neutral with regard to jurisdictional claims in published maps and institutional affiliations.

Copyright: (c) 2021 by the authors Licensee MDPI, Basel, Switzerland. This article is an open access article distributed under the terms and conditions of the Creative Commons Attribution (CC BY) license (https:// creativecommons.org/licenses/by/ $4.0 /)$.

\begin{abstract}
Influenza is one of the most serious respiratory viral infections worldwide. Although several studies have reported that green tea catechins (GTCs) might prevent influenza virus infection, this remains controversial. We performed a systematic review and meta-analysis of eight studies with 5048 participants that examined the effect of GTC administration on influenza prevention. In a random-effects meta-analysis of five RCTs, 884 participants treated with GTCs showed statistically significant effects on the prevention of influenza infection compared to the control group (risk ratio (RR) $0.67,95 \%$ CIs $0.51-0.89, p=0.005)$ without evidence of heterogeneity $\left(I^{2}=0 \%, p=0.629\right)$. Similarly, in three cohort studies with 2223 participants treated with GTCs, there were also statistically significant effects (RR 0.52, 95\% CIs 0.35-0.77, $p=0.001$ ) with very low evidence of heterogeneity $\left(I^{2}=3 \%, p=0.358\right)$. Additionally, the overall effect in the subgroup analysis of gargling and orally ingested items (taking capsules and drinking) showed a pooled RR of 0.62 (95\% CIs 0.49-0.77, $p=0.003)$ without heterogeneity $\left(I^{2}=0 \%, p=0.554\right)$. There were no obvious publication biases (Egger's test $(p=0.138)$ and Begg's test $(p=0.103))$. Our analysis suggests that green tea consumption is effective in the prophylaxis of influenza infections. To confirm the findings before implementation, longitudinal clinical trials with specific doses of green tea consumption are warranted.
\end{abstract}

Keywords: EGCG; green tea catechins; influenza; meta-analysis

\section{Introduction}

Influenza is one of the world's greatest infectious disease challenges. Annual epidemics result in an estimated 3 to 5 million cases of severe illness and approximately 290,000 to 650,000 deaths from respiratory illnesses, particularly during the global winter [1]. Influenza viruses of subtypes $\mathrm{A}(\mathrm{H} 1 \mathrm{~N} 1)$ and $\mathrm{A}(\mathrm{H} 3 \mathrm{~N} 2)$ are currently circulating in humans. The influenza type $B$ viruses currently circulating belong to either the $B /$ Yamagata or the B/Victoria lineages. The virus particles can be transmitted from person to person by respiratory droplets, aerosols, and contact [2,3]. Various hygiene and physical distancing 
measures have helped to reduce the transmission of the influenza virus [4], and while the most effective method of preventing the disease is vaccination, it is not $100 \%$ effective. Therefore, sustained preventive measures are needed to prevent influenza infection.

Various herbal remedies have been used to prevent and treat viral respiratory diseases. Those found to be effective include ginseng and North American ginseng, elderberry, maoto, licorice roots, antiwei, berries, echinacea, plants containing carnosic acid, pomegranate, guava tea, and bai shao [5-8]. Accumulating evidence confirms the therapeutic effect of polyphenols in various models of influenza virus infection, suggesting that polyphenol-rich plants may be considered a new natural source for the development of future anti-influenza drugs [9]. One of these polyphenol-rich plants is green tea.

Green tea is a daily drink consumed throughout the world. One cup $(120 \mathrm{~mL})$ of brewed green tea provides an estimated $150 \mathrm{mg}$ of total catechins, which include the four main catechins: $10-15 \%$ (-) epigallocatechin gallate (EGCG), 6-10\% (-) epigallocatechin (EGC), 2-3\% (-) epicatechin gallate (ECG), and 2\% (-) epicatechin (EC) [10].

Green tea is a source of amino acids, proteins, and lipids, as well as rich in essential chemical compounds such as trace elements and vitamins A, B, C, E, and K [11]. Green tea catechins (GTCs) and EGCG are now receiving considerable attention as having antitumor, antioxidant, anti-inflammatory, anti-diabetes, anti-obesity, anti-hypertension, and antimicrobial infection effects [11,12]. Various evidence suggests that GTCs are an effective antiviral agent, e.g., against influenza and SARS-CoV-2 viruses [13-15]. The stability and bioavailability of GTCs and EGCG as viral preventatives are still unclear. Normally, EGCG reaches a maximum of $1 \mu \mathrm{M}$ in plasma within $2 \mathrm{~h}$ after drinking green tea and is excreted from the blood with a half-life of $5 \mathrm{~h}$ in humans. EGCG is mainly present in free form at about $80 \%$ in plasma, while other catechins are strongly conjugated with glucuronic acid and/or sulfate groups [16]. In rodent studies, EGCG has been found to be distributed in a variety of target organs, such as the digestive tract, blood, brain, liver, kidney, and spleen. EGCG is excreted into feces via bile, while EGC, ECG, and EC are excreted via both bile and urine $[17,18]$. GTCs are metabolized by hepatic and intestinal enzymes and the normal flora of intestinal microorganisms for glucuronidation, sulfation, methylation, and ring cleavage. The bioavailability of orally administered EGCG-enriched GTC capsules after overnight fasting results in the highest EGCG exposure in plasma $[17,19]$. However, EGCG bioavailability shows high interindividual variability related to gastrointestinal absorption, stability of the molecule, nutritional environment, and administration conditions. It is important to note that green tea catechins are more stable at low temperatures and acidic $\mathrm{pH}$ conditions [20-22]. An in vitro study showed that EGCG catechins prevented influenza virus replication by blocking hemagglutinin (HA) in the adsorption phase [23-25]. The hemagglutination inhibition assay (HI) showed that the galloyl group at the 3-position of EGCG and ECG catechins binds to the HA spike on the influenza virus envelope, leading to the inhibition of the attachment activity of the viral HA and sialic acid receptor on red blood cells, and then acting on the acidification of the intracellular compartments of endosomes and lysosomes in the penetration and uncoating phases [26]. EGCG also suppressed viral RNA synthesis by inhibiting viral endonuclease activity [27], and finally blocked the viral progeny release phase by inhibiting influenza neuraminidase activity, which is similar to the mechanism of action of oseltamivir, an active anti-influenza drug [28].

Several clinical studies have been conducted on the anti-influenza effects of catechins following the consumption of green tea via different routes of administration, i.e., drinking brewed green tea, taking green tea capsules as a dietary supplement, or gargling with green tea. Of these, the clinical trials had some limitations, i.e., the size of the population, duration of the study, and the possibility of bias due to residual confounding and unadjusted confounders (occupation, lifestyle including diet, immune function, chronic diseases, etc.) [29]. Therefore, the clinical effects of catechins for the prevention of influenza have remained unclear.

A previous meta-analysis review suggested that green tea catechins may have preventive effects on influenza, but these studies had limitations since they only used green 
tea as a gargle rinse [30,31]. Although several clinical evidence studies have reported that GTCs might prevent influenza virus infection, this remains controversial. Therefore, we performed a systematic review and meta-analysis of randomized controlled trials and prospective cohort studies to evaluate the effect of green tea catechin consumption on the prevention of influenza infection.

\section{Results}

\subsection{Literature Search}

A PRISMA flow diagram is shown in Figure 1. Qualitative and quantitative synthesis searches identified a total of 681 articles (250 articles from Scopus, 103 articles from PubMed, 325 articles from EMBASE, but none found in the Cochrane Central Register of Clinical Trials), and an additional three articles were identified by a review of reference lists. We found 516 articles after removing duplicates and unrelated studies by screening titles and abstracts manually and using Rayyan, an online systemic application. In this way, 12 articles were identified as eligible studies during full-text reading. Unfortunately, four articles were excluded due to the unknown number of participants $(n=2)$ and inappropriate outcome assessment, i.e., evidence of bacterial infection $(n=2)$. Finally, eight studies were included in the analysis.

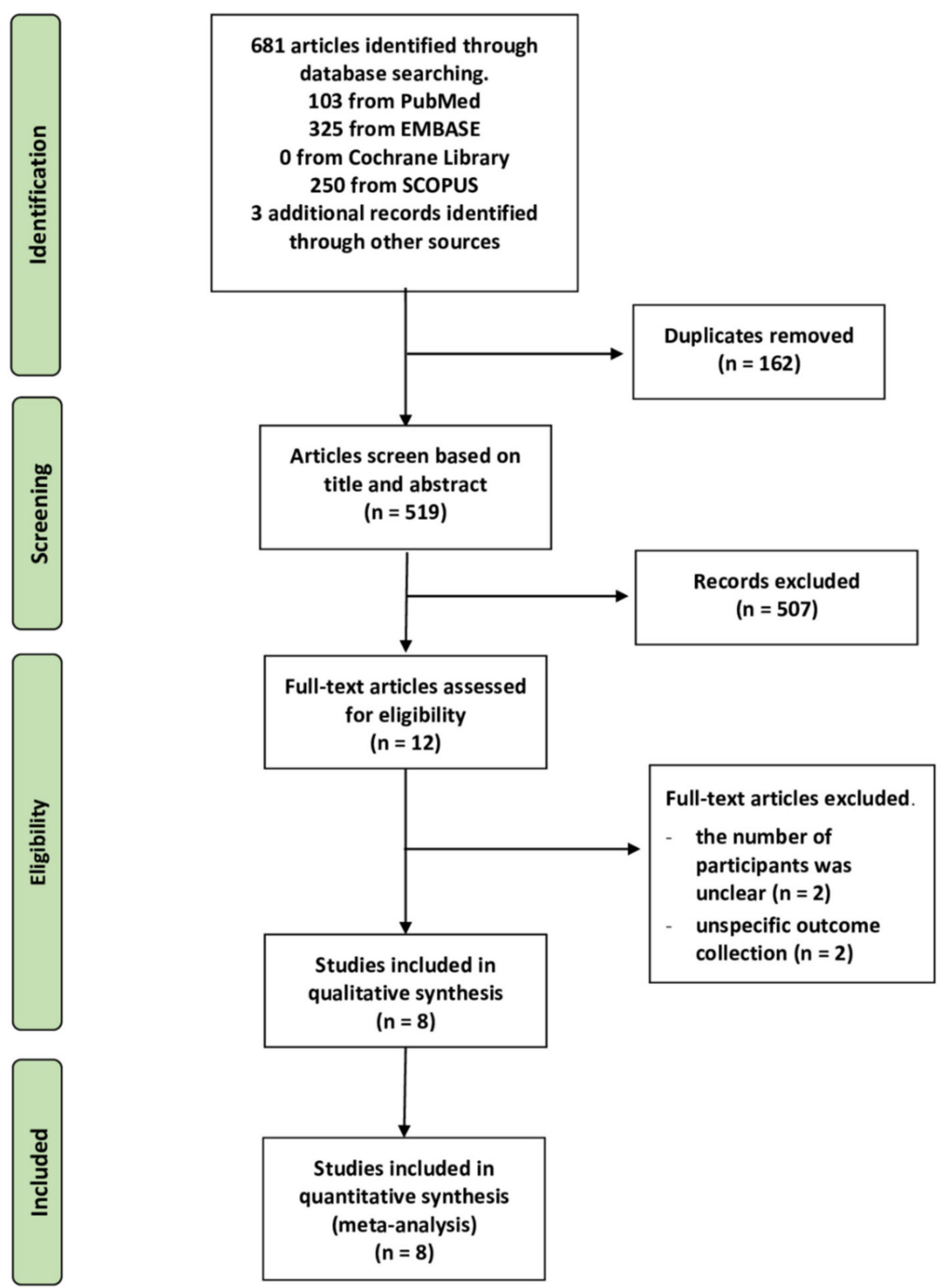

Figure 1. PRISMA flow diagram summary of the study selection process. 


\subsection{Characteristics of the Included Studies}

The main characteristics and results of the included articles are summarized in Table 1. The eight selected studies included five RCTs, with a study duration of 3-5 months [32-36], and three prospective cohort studies, with a study duration of 3-8 months [37-39]. The 5048 participants included were divided into the group taking GTCs (3107 participants) and the group with no treatment (1941 participants). Most of the participants were under 65 years old (there was an age range of 6 to 83 years). Half of them had received the seasonal influenza vaccine. The route of administration of GTCs was by gargling in four studies [33-35,39] by taking GTCs in capsule form in two studies [32,36], and by drinking in two studies [38,39]. The concentration of GTCs taken per day varied from approximately $100 \mathrm{mg}$ to $280 \mathrm{mg}$ for gargling. On the other hand, subjects were randomly assigned to take GTC capsules containing 378 and $1500 \mathrm{mg} /$ day or to consume green tea by drinking 1-5 cups/day or at least 2 cups/week containing 137-685 mg of GTCs (Table 1).

\subsection{Quality Assessment}

Each RCT was confidential and considered to be low risk, as the evaluation of six domains in the Cochrane Risk of Bias (RoB 2.0) tool confirmed. In terms of quality assessment by the RoB 2.0, two studies had a low risk of bias [33,34], one study had a moderate risk of bias [32], and the other two exhibited a serious risk of bias [35,36]. For quality evaluation through NOS, studies were considered high quality if they received a score of 7 stars or more. In this analysis, two studies received 835 or 9 stars [37], with the remaining low quality study receiving 6 stars [38]. However, according to ROBINS-I, one study was of the overall critical quality (Table S2). Details of the quality assessment by the RoB 2.0 and NOS tools are presented in Figure 2 and Table 2, respectively.

\subsection{Clinical Effects of GTCs on Influenza Prevention}

The incidence of influenza infection was defined on the premise of fever (temperature $\geq 37.8^{\circ} \mathrm{C}$ ) and the following clinical signs: chills, cough, sore throat, headache, myalgia, malaise, rhinorrhea, and loss of appetite or diarrhea. Influenza infection was confirmed by laboratory diagnostics, i.e., the detection of viral antigens by an immunochromatographic assay, a rapid antigen detection test commonly used in clinical practice to define influenza virus type A or B [32,34-36,38,39], or cases were confirmed by reverse transcription polymerase chain reaction (RT-PCR), as for the influenza A subtype H1N1 pandemic 2009 (H1N1pdm09). Multiplex PCR was also performed to identify co-infections of seasonal influenza, an influenza A (H3N2) and influenza B, with H1N1pdm09 (Table S1) [37].

Prior to data analysis, heterogeneity among the five RCTs and three cohort studies was assessed (Figure 3 and Table 3 ). The overall $I^{2}$ statistic of both study designs suggested an absence of heterogeneity $\left(I^{2}=0 \% ; p=0.554\right)$; RCTs, $I^{2}=0 \%, p=0.629$, and for the cohort studies, $I^{2}=3 \%, p=0.358$. A forest plot (Figure 3) of the 3,107 participants treated with GTCs showed statistically significant effects on the prevention of influenza infection compared to those in the control group, as evidence by a pooled RR of 0.67 (95\% CIs $0.51-$ 0.89 ) for the five RCTs, and an RR of 0.52 (95\% CIs 0.35-0.77) for the three cohort studies. We then examined the overall effect in a subgroup analysis of the mode of administration, gargle rinse or orally ingested items (taking capsules and drinking). The results of a pooled RR model for the eight studies are shown in Figure 4.

Taking capsules: two studies [32,34] estimated the effect of taking GTC capsules on preventing influenza infection. The overall effect of the pooled RRs demonstrated a significantly reduced risk of influenza (RRs, $0.54 ; 95 \%$ CIs, $0.26-1.13, p=0.003$ ) with a median level of heterogeneity $\left(I^{2}=49 \%, p=0.161\right)$.

Gargling: four studies [33,35-37] assessed the effects of daily gargling with GTCs. The summary effect of the pooled RRs was $0.70(95 \%$ CIs $0.44-1.09, p=0.069)$ with very low evidence of statistical heterogeneity $\left(I^{2}=2 \%, p=0.381\right)$. 
Drinking: the studies presented in $[38,39]$ showed that green tea consumption was significantly associated with influenza prevention. The effect of the pooled RRs was 0.54 (95\% CIs $0.37-0.80, p=0.002)$ without evidence of heterogeneity $\left(I^{2}=0 \%, p=0.636\right)$.

\subsection{Sensitivity and Subgroup Analyses}

The results of the sensitivity and subgroup analyses are shown in Table 3. For sensitivity and subgroup analysis, the data were stratified by study design. The RRs of RCTs were 0.67 (95\% CIs, 0.51-0.89) for a random-effects model and 0.66 (95\% CIs, $0.50-0.88)$ for a fixed-effects model, while the RRs of cohort studies were 0.49 (95\% CIs, $0.33-0.73$ ) for a random-effects model and $0.52(95 \%$ CIs, $0.35-0.77)$ for a fixed-effects model. The sensitivity analysis was then performed after eliminating studies with a high risk of bias $[35,36]$ or low quality of evidence [38]. After removal, the results showed that green tea was still significantly protective against infection caused by the influenza virus. It is important to note that the adverse events occurred in high dose consumption subjects [32]. From toxicological and human safety data, a safe intake level of $338 \mathrm{mg}$ EGCG/day for adults was derived from tea preparations taken as a solid dosage form, and $704 \mathrm{mg}$ EGCG/day could be considered for tea preparations in the beverage form [40]. In the subgroup analysis, results were stratified by EGCG dose, with a cut-off of $338 \mathrm{mg} /$ day.

We found that the effect estimates from such an analysis still showed a trend toward the prevention of influenza infection: RR $0.66,95 \%$ CIs $0.44-1.01$, and RR $0.52,95 \%$ CIs, $0.35-0.77$, for RCTs and cohort studies, respectively (Table 3). At the same time, the route of administration of GTCs was also analyzed. The results showed that all routes of administration (gargling, taking GTC capsules, and drinking) showed efficacy in preventing influenza. The incidence of clinically defined influenza virus infection showed that type A was more common than type B (Table S1), although a proportion of participants had received a seasonal influenza vaccine. It is important to note that influenza vaccination in the group consuming green tea seemed to better prevent influenza infection. For the RCTs, the RR of participants with and without influenza vaccination was 0.36 (95\% CIs $0.15-0.90)$ and 0.72 (95\% CIs 0.54-0.96), respectively. In the cohort studied, the RR of participants with and without influenza vaccination was 0.13 (95\% CIs $0.15-0.90)$ and 0.54 (95\% CIs 0.54-0.96), respectively. The participants in these studies were mixed populations with divided age groups. Participants who were over 65 years old were assigned to the elderly group. This suggests that green tea consumption could be effective for any age group in the studied cohort (RR $0.13,95 \%$ CIs $0.02-1.05$ and RR $0.54,95 \%$ CIs $0.37-0.8$, respectively), regardless of gender (Table 3 ). 
Table 1. Characteristics of the included studies.

\begin{tabular}{|c|c|c|c|c|c|c|c|c|c|c|c|c|c|c|}
\hline \multirow{2}{*}{$\begin{array}{l}\text { Authors } \\
\text { (Year) }\end{array}$} & \multirow{2}{*}{$\begin{array}{l}\text { Study } \\
\text { Design }\end{array}$} & \multirow{2}{*}{$\begin{array}{c}\text { Duration of } \\
\text { Study } \\
\text { (Months) }\end{array}$} & \multirow{2}{*}{$\begin{array}{c}\text { Route of } \\
\text { Administration }\end{array}$} & \multirow{2}{*}{$\begin{array}{l}\text { Experimental } \\
\text { Intervention } \\
\text { GTCs mg/day }\end{array}$} & \multirow{2}{*}{$\begin{array}{l}\text { Age } \\
\text { (Years) }\end{array}$} & \multirow{2}{*}{$\begin{array}{l}\text { Sex } \\
(\mathrm{M} / \mathrm{F})\end{array}$} & \multicolumn{3}{|c|}{$\begin{array}{c}\text { Received Influenza } \\
\text { Vaccination }\end{array}$} & \multicolumn{5}{|c|}{ Clinical Outcome } \\
\hline & & & & & & & Yes & $\begin{array}{l}\text { accinat } \\
\text { No }\end{array}$ & N/A & Flu+ & Flu- & Flu+ & Flu- & Total \\
\hline $\begin{array}{l}\text { Yamada et al. } \\
\text { (2006) [37] }\end{array}$ & Cohort & 3 & Gargling & $\begin{array}{c}100 \mathrm{mg} \\
\text { By } 200 \mu \mathrm{g} / \mathrm{mL} \times 3 \\
\text { times, } 500 \mathrm{~mL}\end{array}$ & $65-83$ & $40 / 84$ & 124 & 0 & 0 & 1 & 75 & 5 & 43 & 124 \\
\hline $\begin{array}{l}\text { Rowe et al. } \\
\text { (2007) [32] }\end{array}$ & RCT & 3 & $\begin{array}{l}\text { Taking } \\
\text { capsules }\end{array}$ & $\begin{array}{c}1500 \mathrm{mg} \\
\text { By } 2 \text { capsules * }\end{array}$ & $18-70$ & $43 / 65$ & 0 & 108 & 0 & 23 & 30 & 35 & 20 & 108 \\
\hline $\begin{array}{l}\text { Yamada et al. } \\
\text { (2007) [33] }\end{array}$ & $\mathrm{RCT}$ & 3 & Gargling & $\begin{array}{c}120 \mathrm{mg} \\
\text { By } 400 \mu \mathrm{g} / \mathrm{mL} \\
\times 3 \text { times, } 300 \mathrm{~mL}\end{array}$ & $20-65$ & NA & 395 & 0 & 0 & 2 & 193 & 4 & 196 & 395 \\
\hline $\begin{array}{c}\text { Matsumoto } \\
\text { et al. (2011) } \\
{[34]}\end{array}$ & $\mathrm{RCT}$ & 5 & $\begin{array}{l}\text { Taking } \\
\text { capsules }\end{array}$ & $\begin{array}{c}378 \mathrm{mg} \\
\text { By } 63 \mathrm{mg} \\
\times 6 \text { capsules }\end{array}$ & $21-69$ & $44 / 152$ & 182 & 14 & 0 & 4 & 93 & 13 & 86 & 196 \\
\hline $\begin{array}{l}\text { Park et al. } \\
\text { (2011) [38] }\end{array}$ & Cohort & 4 & Drinking & $\begin{array}{c}137-685 \mathrm{mg} \\
\text { By } 1-5 \text { cups/day }\end{array}$ & $6-13$ & $991 / 1059$ & 1141 & 854 & 55 & 188 & 1766 & 16 & 80 & 2050 \\
\hline $\begin{array}{c}\text { Toyoizumi } \\
\text { et al. (2013) } \\
{[35]}\end{array}$ & $\mathrm{RCT}$ & 3 & Gargling & $\begin{array}{c}280 \mathrm{mg} \\
\text { By } 560 \mu \mathrm{g} / \mathrm{mL} \\
\times 3 \text { times, } 500 \mathrm{~mL}\end{array}$ & $15-20$ & $184 / 124$ & 130 & 177 & 0 & 11 & 144 & 12 & 140 & 307 \\
\hline $\begin{array}{l}\text { Delabre et al. } \\
\text { (2015) [39] }\end{array}$ & Cohort & 8 & Drinking & $\begin{array}{c}300 \mathrm{mg} \\
\text { By } \leq 2 \text { cups/week }\end{array}$ & $15-50$ & $520 / 601$ & 0 & 1121 & 0 & 8 & 185 & 81 & 847 & 1121 \\
\hline
\end{tabular}

Abbreviations: N/A, not available, ${ }^{*}$ approximately 10 cups/day; $120 \mathrm{~mL} /$ cup contains catechins $150 \mathrm{mg}$ [10]. 


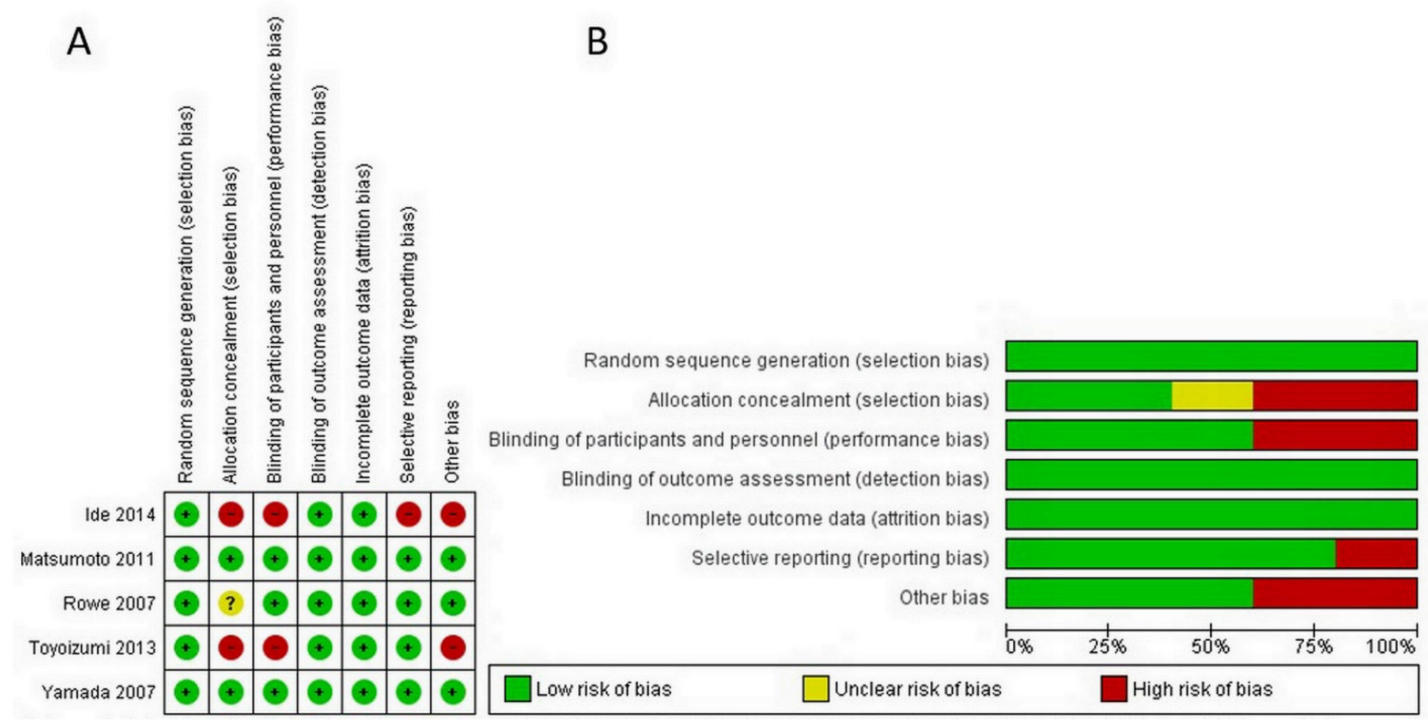

Figure 2. Assessment of risk of bias for RCTs. (A) Risk of bias graph showing each item presented as percentages across all RCT studies (B) Risk of bias summary showing each item for each study.

Table 2. Overall scientific quality of the cohort studies based on the Newcastle-Ottawa Scale (NOS).

\begin{tabular}{cccc}
\hline Study Criterion & Yamada et al. (2006) [37] & Park et al. (2011) [38] & Delabre et al. (2015) [39] \\
\hline Selection (maximum $^{* * * *}$ ) & $* * * *$ & $* * *$ & $* * * *$ \\
Comparability (maximum ${ }^{* *}$ ) & $* *$ & $*$ & $*$ \\
${\text { Outcome }\left(\text { maximum }^{* * *} \text { ) }\right.}^{*}$ & $* * *$ & $* *$ & $* * *$ \\
\hline
\end{tabular}

Note: The symbol * indicates the number corresponding item applies to the study.

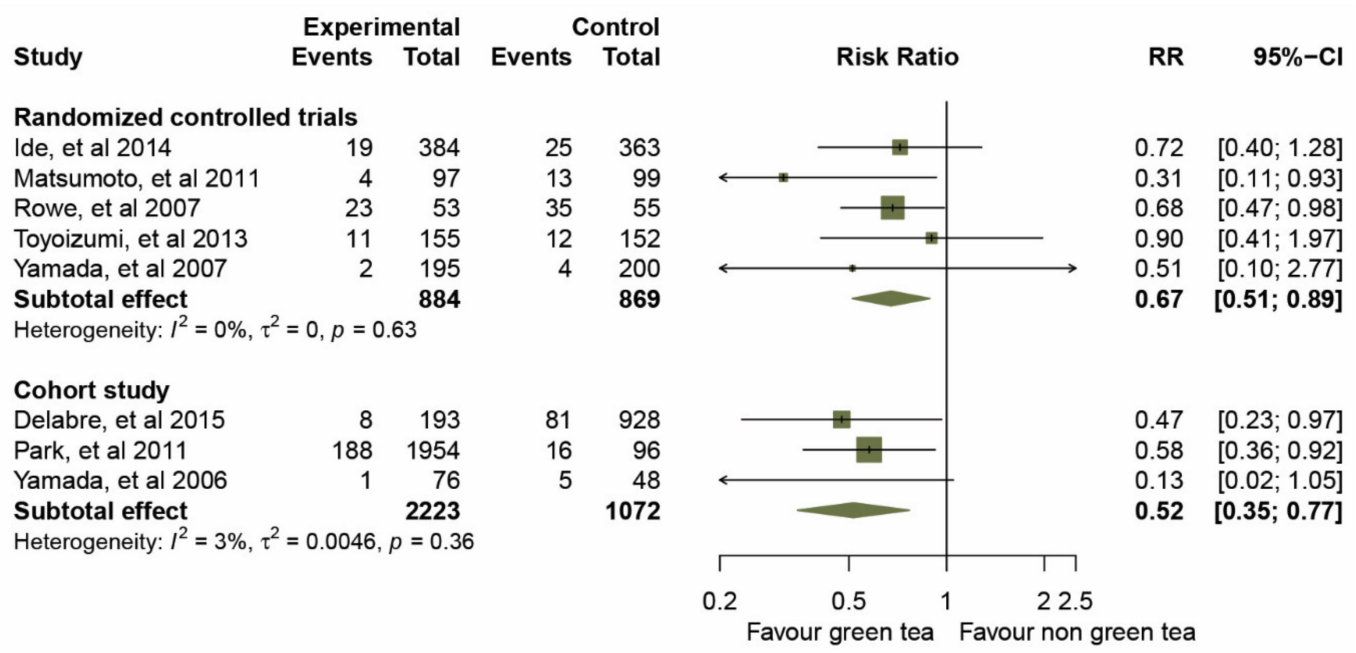

Figure 3. Effect of green tea on preventative influenza virus infection determined by subgroup analysis of RCTs and cohort studies. 
Table 3. Sensitivity and subgroup analysis.

\begin{tabular}{|c|c|c|c|c|c|c|c|c|c|}
\hline \multirow{3}{*}{ Characteristics } & \multicolumn{3}{|c|}{ All Studies } & \multicolumn{3}{|c|}{ Randomized Control Trials } & \multicolumn{3}{|c|}{ Cohort Studies } \\
\hline & \multirow{2}{*}{$\begin{array}{c}\text { Risk Ratio } \\
\text { (95\% CIs) }\end{array}$} & \multicolumn{2}{|c|}{ Heterogeneity } & \multirow{2}{*}{$\begin{array}{c}\text { Risk Ratio } \\
\text { (95\% CIs) }\end{array}$} & \multicolumn{2}{|c|}{ Heterogeneity } & \multirow{2}{*}{$\begin{array}{c}\text { Risk Ratio } \\
\text { (95\% CIs) }\end{array}$} & \multicolumn{2}{|c|}{ Heterogeneity } \\
\hline & & $I^{2}$-Index & $p$-Value & & $I^{2}$-Index & $p$-Value & & $I^{2}$-Index & $p$-Value \\
\hline \multicolumn{10}{|l|}{ Models } \\
\hline - Random effects model & $0.62(0.49 .0 .77)$ & $0.0 \%$ & 0.55 & $0.67(0.51,0.89)$ & $0.0 \%$ & 0.63 & $0.52(0.35,0.77)$ & $3.0 \%$ & 0.36 \\
\hline \multicolumn{10}{|c|}{ Omission of Ide, et al. and Toyoizumi, et al. in the analysis of randomized control trials a } \\
\hline - Before omission & $0.62(0.49 .0 .77)$ & $0.0 \%$ & 0.55 & $0.67(0.51,0.89)$ & $0.0 \%$ & 0.63 & $0.52(0.35,0.77)$ & $3.0 \%$ & 0.36 \\
\hline - After omission & $0.58(0.45,0.74)$ & $0.0 \%$ & 0.45 & $0.62(0.43,0.88)$ & $1.0 \%$ & 0.36 & $0.52(0.35,0.77)$ & $3.0 \%$ & 0.36 \\
\hline - Before omission & $0.62(0.49 .0 .77)$ & $0.0 \%$ & 0.55 & $0.67(0.51,0.89)$ & $0.0 \%$ & 0.63 & $0.52(0.35,0.77)$ & $3.0 \%$ & 0.36 \\
\hline - After omission & $0.63(0.49,0.81)$ & $0.0 \%$ & 0.44 & $0.67(0.51,0.89)$ & $0.0 \%$ & 0.63 & $0.36(0.13,1.03)$ & $26.0 \%$ & 0.24 \\
\hline \multicolumn{10}{|l|}{ Dose of EGCG (mg/day) } \\
\hline - > $338 \mathrm{mg} /$ day & $0.68(0.47,0.98)$ & $\mathrm{N} / \mathrm{A}$ & $\mathrm{N} / \mathrm{A}$ & $0.68(0.47,0.98)$ & $\mathrm{N} / \mathrm{A}$ & $\mathrm{N} / \mathrm{A}$ & $\mathrm{N} / \mathrm{A}$ & $\mathrm{N} / \mathrm{A}$ & $\mathrm{N} / \mathrm{A}$ \\
\hline - $\leq 338 \mathrm{mg} /$ day & $0.58(0.44,0.77)$ & $0.0 \%$ & 0.50 & $0.66(0.44,1.01)$ & $0.0 \%$ & 0.46 & $0.52(0.35,0.77)$ & $3.0 \%$ & 0.36 \\
\hline \multicolumn{10}{|c|}{ Route of administration } \\
\hline - Gargling & $0.70(0.44,1.09)$ & $2.0 \%$ & 0.38 & $0.75(0.48,1.18)$ & $0.0 \%$ & 0.81 & $0.13(0.021 .05)$ & $\mathrm{N} / \mathrm{A}$ & $\mathrm{N} / \mathrm{A}$ \\
\hline - Taking capsules & $0.54(0.26,1.13)$ & $49.0 \%$ & 0.16 & $0.54(0.26,1.13)$ & $49.0 \%$ & 0.16 & $\mathrm{~N} / \mathrm{A}$ & $\mathrm{N} / \mathrm{A}$ & $\mathrm{N} / \mathrm{A}$ \\
\hline - Drinking & $0.54(0.37,0.80)$ & $0.0 \%$ & 0.64 & $\mathrm{~N} / \mathrm{A}$ & $\mathrm{N} / \mathrm{A}$ & $\mathrm{N} / \mathrm{A}$ & $0.54(0.37,0.80)$ & $0.0 \%$ & 0.64 \\
\hline \multicolumn{10}{|l|}{ Type of Influenza virus } \\
\hline - Type A & $0.51(0.10,2.77)$ & $\mathrm{N} / \mathrm{A}$ & $\mathrm{N} / \mathrm{A}$ & $0.51(0.10,2.77)$ & $\mathrm{N} / \mathrm{A}$ & $\mathrm{N} / \mathrm{A}$ & $\mathrm{N} / \mathrm{A}$ & $\mathrm{N} / \mathrm{A}$ & $\mathrm{N} / \mathrm{A}$ \\
\hline - Type B & $0.13(0.021 .05)$ & $\mathrm{N} / \mathrm{A}$ & $\mathrm{N} / \mathrm{A}$ & $\mathrm{N} / \mathrm{A}$ & $\mathrm{N} / \mathrm{A}$ & $\mathrm{N} / \mathrm{A}$ & $0.13(0.021 .05)$ & $\mathrm{N} / \mathrm{A}$ & $\mathrm{N} / \mathrm{A}$ \\
\hline - Type A or B & $0.63(0.50,0.79)$ & $0.0 \%$ & 0.62 & $0.68(0.51,0.90)$ & $0.0 \%$ & 0.48 & $0.54(0.37,0.80)$ & $0.0 \%$ & 0.64 \\
\hline \multicolumn{10}{|c|}{ Received influenza vaccinations (more than 80 percent of participants) } \\
\hline$\bullet$ Yes & $0.31(0.13,0.71)$ & $0.0 \%$ & 0.59 & $0.36(0.15,0.90)$ & $0.0 \%$ & 0.63 & $0.13(0.021 .05)$ & $\mathrm{N} / \mathrm{A}$ & $\mathrm{N} / \mathrm{A}$ \\
\hline$\bullet \mathrm{No}$ & $0.65(0.52,0.82)$ & $0.0 \%$ & 0.76 & $0.72(0.54,0.96)$ & $0.0 \%$ & 0.82 & $0.54(0.37,0.80)$ & $0.0 \%$ & 0.64 \\
\hline \multicolumn{10}{|l|}{ Age over 65 years } \\
\hline - Yes & $0.13(0.021 .05)$ & $\mathrm{N} / \mathrm{A}$ & $\mathrm{N} / \mathrm{A}$ & $\mathrm{N} / \mathrm{A}$ & $\mathrm{N} / \mathrm{A}$ & $\mathrm{N} / \mathrm{A}$ & $0.13(0.021 .05)$ & $\mathrm{N} / \mathrm{A}$ & $\mathrm{N} / \mathrm{A}$ \\
\hline - No & $0.63(0.50,0.79)$ & $0.0 \%$ & 0.73 & $0.67(0.51,0.89)$ & $0.0 \%$ & 0.63 & $0.54(0.37,0.80)$ & $0.0 \%$ & 0.64 \\
\hline
\end{tabular}

Abbreviations: CIs, confidence intervals; N/A, not available; EGCG, epigallocatechin gallate. ${ }^{\text {a }}$ Selected for high risk of bias; ${ }^{\mathrm{b}}$ Selected from Newcastle-Ottawa Scale (less than 7 stars). 


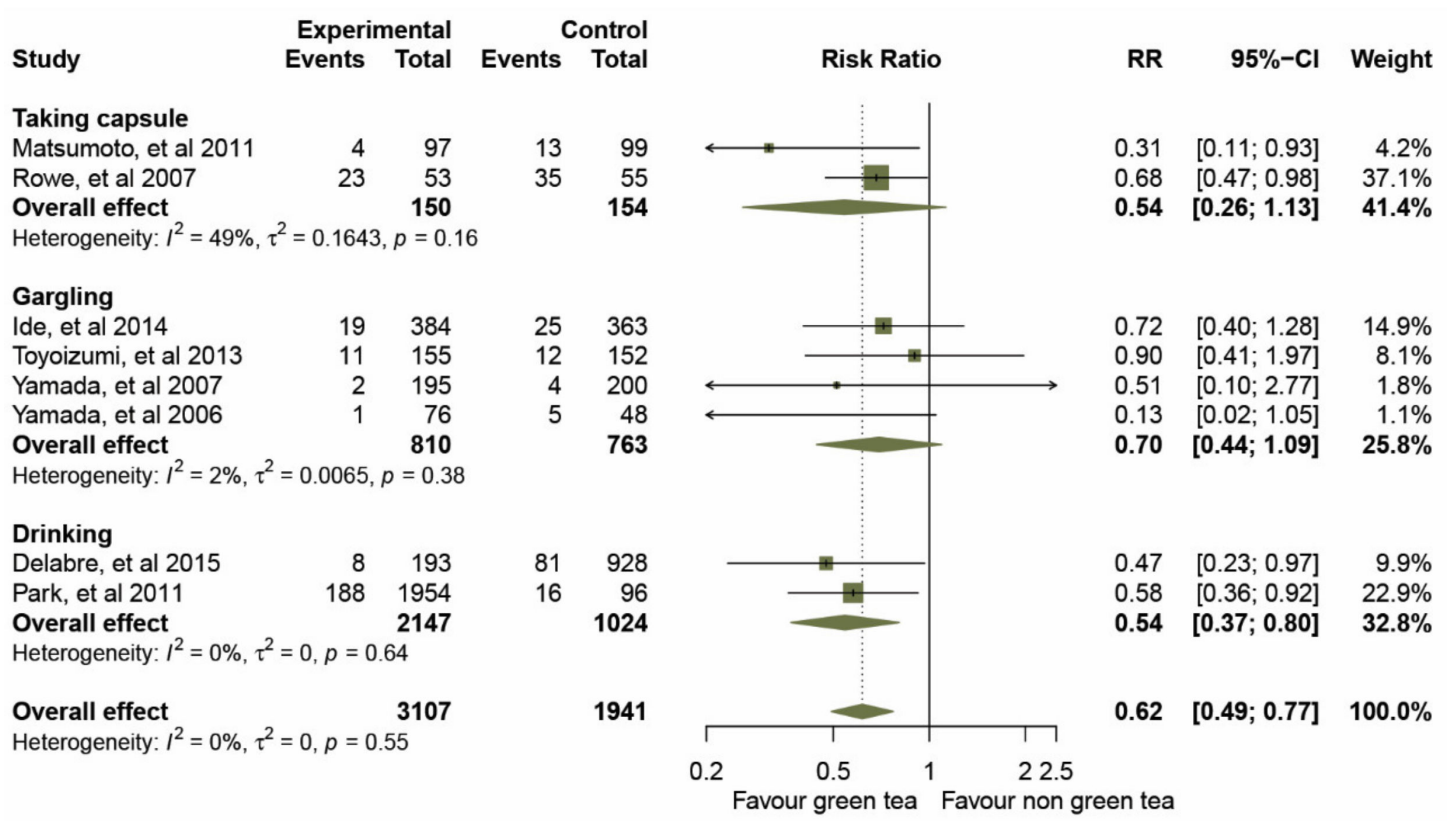

Figure 4. Effect of green tea on preventing influenza virus infection determined by route of administration.

\subsection{Publication Bias of Included Studies}

The potential publication bias of the eight included studies is illustrated by a funnel plot (Figure S1). As only a small number of articles were included in this study, the visual translation of the plot may be uncertain. However, Begg's test and Egger's test analyses showed no significant difference ( $p=0.138$ and $p=0.103$, respectively).

\section{Discussion}

We conducted a systematic review and meta-analysis to evaluate the possibility that green tea catechins prevent influenza infection. We found that participants with a history of green tea consumption showed a significant association with improved influenza prevention, with a small degree of heterogeneity. Based on these findings, it appears that consuming $137-685 \mathrm{mg}$ of green tea catechin per day (1-5 cups), taking 378-1500 $\mathrm{mg}$ of supplement capsules per day, or gargling $100-280 \mathrm{mg}$ per day is an ideal catechin level for influenza prevention. However, the EGCG concentration of green tea preparations should be stated as the output to avoid hepatotoxicity. Based on $1 \mathrm{~g}$ leaf $/ 100 \mathrm{~mL}$ infusion, brewed green tea contains an average of $126.6 \mathrm{mg}$ total catechins and 77.8 mg EGCG per $100 \mathrm{~mL}$ as consumed, according to the United States Department of Agriculture (USDA) Flavonoid Database. As a result, each $240 \mathrm{~mL}$ serving of brewed green tea could contain $304 \mathrm{mg}$ total catechins, including $187 \mathrm{mg}$ EGCG. As a result, for people who drink three 8 oz. cups of green tea per day, daily catechin and EGCG intakes are reported to be around 912 and $560 \mathrm{mg}$, respectively [41]. A systematic review of adverse event data from 159 human studies revealed results consistent with toxicological findings that a limited range of concentrated, catechin-rich green tea preparations resulted in hepatic adverse events in a dose-dependent manner when taken in large bolus doses, but not when consumed as brewed tea or extracts in beverages or as part of the diet [40]. In rare cases, adverse events such as flatulence, stomach upset, dizziness, rash, and constipation have been reported when taking supplement capsules with EGCG concentrations greater than $338 \mathrm{mg} /$ day [32] This should be considered. 


\subsection{Comparison with Other Studies}

The analysis of each route of administration of GTCs (gargling, taking GTC capsules, or drinking) showed efficacy in preventing influenza. Previously, a meta-analysis of gargling with green and black tea to prevent influenza infection was reported by Ide's group [31]; the data from the RCTs were then reanalyzed by the same research group using Bayesian approaches [30]. The results suggested that gargling with green tea may slightly reduce influenza compared to gargling with water, which is similar to this study (RR, 0.75 (95\% CIs 0.48-1.18) of RCTs events). Consequently, regular gargling with GTCs is a choice for preventing influenza-like infections for those who dislike drinking brewed green tea. On the other hand, drinking green tea or taking GTC supplements that contain catechin active compounds at two and five times the concentration of gargling solution are also able to significantly prevent influenza infection. However, the number of studies is very small: two cohorts of drinking and two RCTs of taking capsules. Therefore, further studies are needed to confirm this finding. In addition, RCTs have shown that drinking green tea catechins prevents infection not only by the influenza virus, but also by other upper respiratory infectious viruses such as respiratory syncytial virus, adenovirus, and rhinovirus [42,43].

The mechanism of action of GTCs against influenza viruses in an in vitro study has already been mentioned. In an in vivo and ex vivo study, EGCG and other catechins were shown to activate $\mathrm{T}$ cell function by increasing the IL- 12 and IFN- $\gamma$ secretion to defend and respond to influenza infection and also enhance the antigenic challenge with an antiinflammatory effect [32,44]. Moreover, not only catechin but also theanine, a non-protein amino acid of green tea, might be involved in the accumulation of $T$ cell functions [34]. Nevertheless, the bioavailability of catechins via oral administration may be individually important for a therapeutic effect [45]. Gargling involves rinsing the mouth and throat with a liquid that is kept moving by breathing through it with a gurgling sound [46]. Although there are reports suggesting the prevention of influenza by gargling, it should be noted that the mechanism of prevention of these respiratory infections by gargling is unclear. Therefore, a more detailed study is needed to verify the effects of the prevention of influenza and whether this is a direct effect of gargling itself or the effect of catechin.

\subsection{Clinical Implication}

The highest incidence of clinically defined influenza virus infection is reported for type A. This is consistent with the WHO finding that only type A influenza viruses are known to cause pandemics [1]. In a prospective household cohort study by Delabre's group, pandemic influenza $\mathrm{A} / \mathrm{H} 1 \mathrm{~N} 1 \mathrm{pdm} 09$ was found to be co-infected with seasonal influenza A (H3N2) and influenza B in 68\% (30/44) and 27\% (10/37), respectively [39]. Participants who were vaccinated with the seasonal influenza vaccine before participating in the study could also contribute to influenza prevention. It is important to note that the influenza vaccine seems to be more effective in preventing influenza infection in the group that consumed green tea. Seasonal influenza vaccination is especially important for people who are at high risk of influenza complications and for people who live with or care for people at high risk, such as pregnant women, children aged 6 months to 5 years old, elderly people (over 65 years of age), people with chronic illnesses, and healthcare workers [47]. Therefore, future studies need to clarify the potential for catechins to serve as an effective influenza vaccination and should be performed for the evaluation of its effectiveness in longitudinal clinical trials.

\subsection{Strengths and Limitations}

The strengths of this study should be highlighted as follows. We conducted a comprehensive search of four major databases (PubMed, SCOPUS, Embase, and Cochrane Library), which is a standard method for conducting a systematic review without restrictions on language or study design. We performed a rigorous assessment of the methodological quality of the included studies, as determined by the ROBINS-I and NOS. The results 
showed consistency in terms of the quality of the studies included. This meta-analysis adhered to the standard methodology of systematic reviews and meta-analyses as required by the PRISMA checklist (see Supplementary Materials-Table S3). Finally, our study covered the current evidence and was conducted using appropriate statistical methods for the analyses.

However, our study also had some limitations. Because present studies do not show publication bias suggesting that green tea consumption may prevent influenza, a smaller number of clinical trial reports may have been affected by the analysis. Therefore, we suggest that consensus needs to be established or confirmed on a larger scale with more detailed instructions in future studies, especially in RCTs investigating daily green tea consumption. It is important to note that the comparison of each mode of green tea consumption, i.e., drinking, gargling, or taking a dietary supplement with GTCs, was not completed in this study due to the limited number of subjects. Moreover, the effect remains inconclusive in the more sensitive groups, i.e., the ingredients and formulation of the intervention. The cultivation area and extraction process of green tea are related to the quality and stability of active catechin content, including brewing conditions, sterilization, $\mathrm{pH}$, storage time, and temperature [48-50]. The home environment, social contacts, and use of public transportation have a high risk of exposing individuals to influenza viruses. Asthma and chronic obstructive pulmonary disease have been identified as possible risk factors for influenza infection [47,51]. In addition to preventing influenza by consuming green tea, personal hygiene is important for attenuating influenza. Hand hygiene and face masks appear to prevent influenza virus transmission when performed within $36 \mathrm{~h}$ of the onset of symptoms in the patient [52-54].

Finally, the results of this report can provide an additional measure for influenza prevention, and could be considered an alternative option to a pharmaceutical strategy. Regarding the oral administration of EGCG, this reduced the mortality rate of influenza infection, which was equivalent to the oral administration of oseltamivir in mice [55]. Consequently, EGCG treatment alone or in combination with therapy with anti-influenza drugs may be used as a treatment of choice for influenza drug-resistant variants, which have been frequently reported [56].

\section{Materials and Methods}

This study was performed according to the Preferred Reporting Items for Systematic Reviews and Meta-Analyses (PRISMA) statement [57]. This study was registered on PROSPERO (registration number: CRD42020176371) [58].

\subsection{Search Strategies}

We searched PubMed, Scopus, Embase, and the Cochrane Central Register of Clinical Trials for relevant original research articles published from inception up to February 2021. The search strategy was carried out with the following keywords: "green tea," "catechin," "epigallocatechin gallate," "influenza," "flu," and "common cold," with slight adjustments depending on the database. No restrictions were placed on language, publication date, or publication status. We also screened the references of articles and published systematic reviews for additional relevant studies.

The article was included if the following inclusion criteria were met: (1) conducted in humans, (2) investigated the clinical effect of green tea or catechin in preventing influenza infection, and (3) included a control group. Two authors (Anchalee Rawangkan (A.R.) and Surasak Saokaew (S.S.)) independently reviewed all titles and abstracts to clarify whether the studies evaluated the clinical effects of green tea or catechin according to the inclusion criteria, and then analyzed data from potential full-text articles. When inconsistencies and instabilities regarding qualification arose, they were resolved by consensus. 


\subsection{Data Extraction and Outcome Measures}

Two investigators (A.R. and S.S.) extracted the data, which were confirmed by Kirati Kengkla (K.K.) and Sukrit Kanchanasurakit (S.K.). The data extraction form included the following information: study design, duration, number of participants, participant age, participant sex, route of administration (gargling, drinking or taking capsules), concentration of GTCs consumed per day, outcome measurement, type of influenza virus infection, and influenza vaccine history of the participant. Outcomes of interest depended on influenza prevention; for example, laboratory-confirmed antigen tests of influenza viruses showed negative results.

\subsection{Quality Assessment}

Two investigators (A.R. and K.K.) performed quality assessment of each study using the Cochrane Collaboration Risk of Bias tool for randomized controlled trials (RoB 2.0) [59]. The Risk Of Bias In Non-randomized Studies of Interventions (ROBINS-I) tool [60] and the Newcastle-Ottawa Scale (NOS) [61] were used for observational studies. The six domains of the Cochrane tool assessed selection bias, performance bias, detection bias, attrition bias, reporting bias, and other sources of bias. Each domain of an RCT study was classified as unclear, low, or high risk. ROBINS-I, a new tool for assessing the risk of bias in estimates of comparative effectiveness of interventions from studies that did not use randomization to assign units to comparison groups, was assessed using the following seven domains: confounding domain, selection of participants into the study, classification of interventions, deviation from intended interventions, missing data, measurement of outcomes, and selection of reported outcomes. The NOS performed a star rating system for the qualification of the three domains, i.e., selection of study groups, comparability of groups, and coverage of the outcome of interest. Each domain of the NOS was rated as unclear (no star), low risk (one or more stars), or high risk (no star), for a total of nine stars, with studies reporting a total score of 7 being defined as high quality. Differences between analysts were resolved through discussion and agreement as to the final decision.

\subsection{Statistical Analysis}

Risk ratio (RR), a ratio of the risk of influenza among green tea and non-green tea groups, were estimated with $95 \%$ confidence intervals (CIs) for dichotomous outcomes. A risk ratio of 1.0 indicates identical risk among the two groups. $R R>1.0$ indicates an increased risk of influenza in the green tea group, and $R R<1.0$ indicates a decreased risk of influenza in the green tea group. In addition, standardized mean differences (SMDs) with $95 \%$ CIs were used for continuous outcomes. Heterogeneity was assessed using the Cochrane $\mathrm{Q}$ statistic and quantified using the $I^{2}$ statistic [62]. A random-effects model was used to assess pooled RRs and 95\% CIs [63,64]. We then assessed small-study effects using Begg's test, Egger's regression asymmetry test, and visual inspection of the funnel plot, whose asymmetric shape indicates the presence of bias [65]. Subgroup and sensitivity analyses were performed to examine the influence of each variable based on the baseline characteristics of each study, including: 1) models (fixed effect model and random effect model); 2) dose of epigallocatechin gallate (EGCG);3) route of administration; 4) type of influenza virus; 5 ) history of participants with respect to the influenza vaccine (more than 80 percent of participants having received vaccinations); and 6) participant age. Articles with high risk of bias or low quality of evidence (NOS less than 7 stars) were omitted. Statistical tests were two-sided, with $p$-values of 0.05 indicating statistical significance.

\section{Conclusions}

This meta-analysis shows that regular green tea consumption, whether by taking GTC capsules, drinking, or gargling, can prevent influenza, although the study populations were from different countries, the treatment regimens were different, and the number of studies on tea catechins against influenza was limited. Further studies are needed to better investigate the processes described for individual and collective treatment with green tea. 
Future large-scale studies are needed to establish or confirm their clinical efficacy. Most importantly, it must be clearly emphasized that green tea catechins cannot replace standard influenza vaccination or treatment. Nevertheless, their beneficial effects may support common influenza prevention.

Supplementary Materials: Figure S1: Funnel plot with pseudo 95\% confidence limits, Table S1: Event of type of influenza virus infection and EGCG consumption concentrations, Table S2; The Risk Of Bias In Non-randomized Studies of Interventions (ROBINS-I) tool, Table S3: The PRISMA statement checklist.

Author Contributions: A.R. and S.S. contributed to the research idea and design. A.R. and S.S. created the search strategy. A.R. and S.S. screened titles, abstracts, and full texts. A.R., K.K. and S.K. contributed to data extraction and quality assessment. A.R., K.K., S.K. and S.S. contributed to the statistical analysis and interpretation of data. A.R. wrote the first draft of the manuscript. K.K., S.K., A.D. and S.S. edited the draft of the manuscript. All authors have read and agreed to the published version of the manuscript.

Funding: This research was funded by the Unit of Excellence on Clinical Outcomes Research and IntegratioN (UNICORN) [Grant number: FF64-UoE003], School of Pharmaceutical Sciences, University of Phayao. The funding source had no role in the study design, collection, analysis, and interpretation of data.

Institutional Review Board Statement: The systematic review and meta-analysis are exempt from ethics approval because data were collected and synthesized from previous studies. The patient data are anonymized and available in the public domain. The authors followed applicable EQUATOR Network (https://www.equator-network.org, accessed on 30 June 2021) guidelines during the conduct of research project.

Informed Consent Statement: Not applicable.

Data Availability Statement: The data presented in this study are available in this article.

Acknowledgments: We are grateful to Emma Taylor, PhD, from PRS Group for proofreading and English language review.

Conflicts of Interest: The authors declare no conflict of interest.

\section{References}

1. WHO. Fact Sheets Influenza (Seasonal). Available online: https://www.who.int/news-room/fact-sheets/detail/influenza (accessed on 11 June 2021).

2. Boktor, S.W.; Hafner, J.W. Influenza. In StatPearls; StatPearls Publishing: Treasure Island, FL, USA, 2021.

3. Killingley, B.; Nguyen-Van-Tam, J. Routes of influenza transmission. Influenza Other Respir. Viruses 2013, 7 (Suppl. 2), $42-51$. [CrossRef] [PubMed]

4. Macintyre, C.; Wang, Q. Physical distancing, face masks, and eye protection for prevention of COVID-19. Lancet 2020, 395. [CrossRef]

5. Antonelli, M.; Donelli, D.; Firenzuoli, F. Ginseng integrative supplementation for seasonal acute upper respiratory infections: A systematic review and meta-analysis. Complementary Ther. Med. 2020, 52, 102457. [CrossRef] [PubMed]

6. Hawkins, J.; Baker, C.; Cherry, L.; Dunne, E. Black elderberry (Sambucus nigra) supplementation effectively treats upper respiratory symptoms: A meta-analysis of randomized, controlled clinical trials. Complement. Med. 2019, 42, 361-365. [CrossRef] [PubMed]

7. Mousa, H.A. Prevention and Treatment of Influenza, Influenza-Like Illness, and Common Cold by Herbal, Complementary, and Natural Therapies. J. Evid. Based. Complementary Altern. Med. 2017, 22, 166-174. [CrossRef] [PubMed]

8. Wieland, L.S.; Piechotta, V.; Feinberg, T.; Ludeman, E.; Hutton, B.; Kanji, S.; Seely, D.; Garritty, C. Elderberry for prevention and treatment of viral respiratory illnesses: A systematic review. BMC Complement. Med. 2021, 21, 112. [CrossRef]

9. Bahramsoltani, R.; Sodagari, H.R.; Farzaei, M.H.; Abdolghaffari, A.H.; Gooshe, M.; Rezaei, N. The preventive and therapeutic potential of natural polyphenols on influenza. Expert Rev. Anti Infect. 2016, 14, 57-80. [CrossRef]

10. Fujiki, H.; Suganuma, M.; Imai, K.; Nakachi, K. Green tea: Cancer preventive beverage and/or drug. Cancer Lett. 2002, 188, 9-13. [CrossRef]

11. Musial, C.; Kuban-Jankowska, A.; Gorska-Ponikowska, M. Beneficial Properties of Green Tea Catechins. Int. J. Mol. Sci. 2020, 21, 1744. [CrossRef] 
12. Rawangkan, A.; Wongsirisin, P.; Namiki, K.; Iida, K.; Kobayashi, Y.; Shimizu, Y.; Fujiki, H.; Suganuma, M. Green Tea Catechin Is an Alternative Immune Checkpoint Inhibitor that Inhibits PD-L1 Expression and Lung Tumor Growth. Molecules 2018, $23,2071$. [CrossRef]

13. Furushima, D.; Ide, K.; Yamada, H. Effect of Tea Catechins on Influenza Infection and the Common Cold with a Focus on Epidemiological/Clinical Studies. Molecules 2018, 23, 1795. [CrossRef] [PubMed]

14. Ohgitani, E.; Shin-Ya, M.; Ichitani, M.; Kobayashi, M.; Takihara, T.; Kawamoto, M.; Kinugasa, H.; Mazda, O. Significant Inactivation of SARS-CoV-2 In Vitro by a Green Tea Catechin, a Catechin-Derivative, and Black Tea Galloylated Theaflavins. Molecules 2021, 26, 3572. [CrossRef]

15. Xu, J.; Xu, Z.; Zheng, W. A Review of the Antiviral Role of Green Tea Catechins. Molecules 2017, 22, 1337. [CrossRef]

16. Chow, H.H.S.; Hakim, I.A. Pharmacokinetic and chemoprevention studies on tea in humans. Pharm. Res 2011, 64, 105-112. [CrossRef]

17. Liu, A.B.; Tao, S.; Lee, M.-J.; Hu, Q.; Meng, X.; Lin, Y.; Yang, C.S. Effects of gut microbiota and time of treatment on tissue levels of green tea polyphenols in mice. Biofactors 2018. [CrossRef]

18. Suganuma, M.; Okabe, S.; Oniyama, M.; Tada, Y.; Ito, H.; Fujiki, H. Wide distribution of [3H](-)-epigallocatechin gallate, a cancer preventive tea polyphenol, in mouse tissue. Carcinogenesis 1998, 19, 1771-1776. [CrossRef]

19. Andreu-Fernández, V.; Almeida Toledano, L.; Pizarro, N.; Navarro-Tapia, E.; Gómez-Roig, M.D.; de la Torre, R.; García-Algar, Ó. Bioavailability of Epigallocatechin Gallate Administered with Different Nutritional Strategies in Healthy Volunteers. Antioxidants 2020, 9, 440. [CrossRef] [PubMed]

20. Cabrera, M.; Taher, F.; Llantada, A.; Do, Q.; Sapp, T.; Sommerhalter, M. Effect of Water Hardness on Catechin and Caffeine Content in Green Tea Infusions. Molecules 2021, 26, 3485. [CrossRef]

21. Friedman, M.; Levin, C.E.; Lee, S.U.; Kozukue, N. Stability of green tea catechins in commercial tea leaves during storage for 6 months. J. Food Sci. 2009, 74, H47-H51. [CrossRef] [PubMed]

22. Feng, W.Y. Metabolism of green tea catechins: An overview. Curr. Drug. Metab. 2006, 7, 755-809. [CrossRef] [PubMed]

23. Kaihatsu, K.; Yamabe, M.; Ebara, Y. Antiviral Mechanism of Action of Epigallocatechin-3-O-gallate and Its Fatty Acid Esters. Molecules 2018, 23, 2475. [CrossRef] [PubMed]

24. Song, J.-M.; Lee, K.-H.; Seong, B.-L. Antiviral effect of catechins in green tea on influenza virus. Antivir. Res. 2005, 68, 66-74. [CrossRef]

25. Nakayama, M.; Suzuki, K.; Toda, M.; Okubo, S.; Hara, Y.; Shimamura, T. Inhibition of the infectivity of influenza virus by tea polyphenols. Antivir. Res 1993, 21, 289-299. [CrossRef]

26. Imanishi, N.; Tuji, Y.; Katada, Y.; Maruhashi, M.; Konosu, S.; Mantani, N.; Terasawa, K.; Ochiai, H. Additional inhibitory effect of tea extract on the growth of influenza A and B viruses in MDCK cells. Microbiol. Immunol. 2002, 46, 491-494. [CrossRef] [PubMed]

27. Kuzuhara, T.; Iwai, Y.; Takahashi, H.; Hatakeyama, D.; Echigo, N. Green tea catechins inhibit the endonuclease activity of influenza A virus RNA polymerase. PLoS Curr. 2009, 1, RRN1052. [CrossRef] [PubMed]

28. Müller, P.; Downard, K.M. Catechin inhibition of influenza neuraminidase and its molecular basis with mass spectrometry. $J$. Pharm. Biomed. Anal. 2015, 111, 222-230. [CrossRef]

29. Nanri, A.; Nakamoto, K.; Sakamoto, N.; Imai, T.; Mizoue, T. Green tea consumption and influenza infection among Japanese employees. Eur. J. Clin. Nutr. 2021, 75, 976-979. [CrossRef] [PubMed]

30. Ide, K.; Kawasaki, Y.; Akutagawa, M.; Yamada, H. Effects of Green Tea Gargling on the Prevention of Influenza Infection: An Analysis Using Bayesian Approaches. J. Altern. Complement. Med. 2017, 23, 116-120. [CrossRef]

31. Ide, K.; Yamada, H.; Kawasaki, Y. Effect of gargling with tea and ingredients of tea on the prevention of influenza infection: A meta-analysis. BMC Public Health 2016, 16, 396. [CrossRef]

32. Rowe, C.A.; Nantz, M.P.; Bukowski, J.F.; Percival, S.S. Specific formulation of Camellia sinensis prevents cold and flu symptoms and enhances gamma, delta T cell function: A randomized, double-blind, placebo-controlled study. J. Am. Coll. Nutr. 2007, 26, 445-452. [CrossRef]

33. Yamada, H.; Daimon, T.; Matsuda, K.; Yoshida, M.; Takuma, N.; Hara, Y. A Randomized Controlled Study on the Effects of Gargling with Tea Catechin Extracts on the Prevention of Influenza Infection in Healthy Adults. Rinsho Yakuri/Jpn. J. Clin. Pharmacol. Ther. 2007, 38, 323-330. [CrossRef]

34. Matsumoto, K.; Yamada, H.; Takuma, N.; Niino, H.; Sagesaka, Y.M. Effects of green tea catechins and theanine on preventing influenza infection among healthcare workers: A randomized controlled trial. BMC Complement. Altern. Med. 2011, 11, 15. [CrossRef]

35. Toyoizumi, K.; Yamada, H.; Matsumoto, K.; Sameshima, Y. Gargling with Green Tea for Influenza Prophylaxis: A Pilot Clinical Study. Rinsho Yakuri/Jpn. J. Clin. Pharmacol. Ther. 2013, 44, 459-461. [CrossRef]

36. Ide, K.; Yamada, H.; Matsushita, K.; Ito, M.; Nojiri, K.; Toyoizumi, K.; Matsumoto, K.; Sameshima, Y. Effects of green tea gargling on the prevention of influenza infection in high school students: A randomized controlled study. PLoS ONE 2014, 9, e96373. [CrossRef] [PubMed]

37. Yamada, H.; Takuma, N.; Daimon, T.; Hara, Y. Gargling with tea catechin extracts for the prevention of influenza infection in elderly nursing home residents: A prospective clinical study. J. Altern. Complement. Med. 2006, 12, 669-672. [CrossRef] 
38. Park, M.; Yamada, H.; Matsushita, K.; Kaji, S.; Goto, T.; Okada, Y.; Kosuge, K.; Kitagawa, T. Green tea consumption is inversely associated with the incidence of influenza infection among schoolchildren in a tea plantation area of Japan. J. Nutr. 2011, 141, 1862-1870. [CrossRef] [PubMed]

39. Delabre, R.M.; Lapidus, N.; Salez, N.; Mansiaux, Y.; de Lamballerie, X.; Carrat, F. Risk factors of pandemic influenza A/H1N1 in a prospective household cohort in the general population: Results from the CoPanFlu-France cohort. Influenza Other Respir. Viruses 2015, 9, 43-50. [CrossRef]

40. Hu, J.; Webster, D.; Cao, J.; Shao, A. The safety of green tea and green tea extract consumption in adults-Results of a systematic review. Regul. Toxicol. Pharm. 2018, 95, 412-433. [CrossRef]

41. NIH. Green Tea Dietary Supplement Pilot Study. Available online: https://www.dietarysupplementdatabase.usda.nih.gov/ dsid_database/Res\%20Summ\%20Green\%20Tea\%201-8-2-17final.pdf (accessed on 11 June 2021).

42. Kalus, U.; Kiesewetter, H.; Radtke, H. Effect of CYSTUS052 and green tea on subjective symptoms in patients with infection of the upper respiratory tract. Phytother. Res. 2010, 24, 96-100. [CrossRef] [PubMed]

43. Furushima, D.; Nishimura, T.; Takuma, N.; Iketani, R.; Mizuno, T.; Matsui, Y.; Yamaguchi, T.; Nakashima, Y.; Yamamoto, S.; Hibi, M.; et al. Prevention of Acute Upper Respiratory Infections by Consumption of Catechins in Healthcare Workers: A Randomized, Placebo-Controlled Trial. Nutrients 2019, 12, 4. [CrossRef]

44. Kamath, A.B.; Wang, L.; Das, H.; Li, L.; Reinhold, V.N.; Bukowski, J.F. Antigens in tea-beverage prime human Vgamma 2Vdelta 2 T cells in vitro and in vivo for memory and nonmemory antibacterial cytokine responses. Proc. Natl. Acad. Sci. USA 2003, 100, 6009-6014. [CrossRef]

45. Cai, Z.Y.; Li, X.M.; Liang, J.P.; Xiang, L.P.; Wang, K.R.; Shi, Y.L.; Yang, R.; Shi, M.; Ye, J.H.; Lu, J.L.; et al. Bioavailability of Tea Catechins and Its Improvement. Molecules 2018, 23, 2346. [CrossRef] [PubMed]

46. Satomura, K.; Kitamura, T.; Kawamura, T.; Shimbo, T.; Watanabe, M.; Kamei, M.; Takano, Y.; Tamakoshi, A. Prevention of upper respiratory tract infections by gargling: A randomized trial. Am. J. Prev. Med. 2005, 29, 302-307. [CrossRef]

47. Castilla, J.; Godoy, P.; Domínguez, Á.; Martín, V.; Delgado-Rodríguez, M.; Martínez-Baz, I.; Baricot, M.; Soldevila, N.; Mayoral, J.M.; Astray, J.; et al. Risk factors and effectiveness of preventive measures against influenza in the community. Influenza Other Respir. Viruses 2013, 7, 177-183. [CrossRef] [PubMed]

48. Chen, Z.; Zhu, Q.Y.; Tsang, D.; Huang, Y. Degradation of green tea catechins in tea drinks. J. Agric. Food. Chem. 2001, 49, 477-482. [CrossRef]

49. Koch, W.; Kukula-Koch, W.; Komsta, Ł.; Marzec, Z.; Szwerc, W.; Głowniak, K. Green Tea Quality Evaluation Based on Its Catechins and Metals Composition in Combination with Chemometric Analysis. Molecules 2018, 23, 1689. [CrossRef] [PubMed]

50. Jin, Y.; Zhao, J.; Kim, E.M.; Kim, K.H.; Kang, S.; Lee, H.; Lee, J. Comprehensive Investigation of the Effects of Brewing Conditions in Sample Preparation of Green Tea Infusions. Molecules 2019, 24, 1735. [CrossRef]

51. Lapidus, N.; de Lamballerie, X.; Salez, N.; Setbon, M.; Delabre, R.M.; Ferrari, P.; Moyen, N.; Gougeon, M.L.; Vely, F.; Leruez-Ville, M.; et al. Factors associated with post-seasonal serological titer and risk factors for infection with the pandemic A/H1N1 virus in the French general population. PLoS ONE 2013, 8, e60127. [CrossRef]

52. Cowling, B.J.; Chan, K.H.; Fang, V.J.; Cheng, C.K.; Fung, R.O.; Wai, W.; Sin, J.; Seto, W.H.; Yung, R.; Chu, D.W.; et al. Facemasks and hand hygiene to prevent influenza transmission in households: A cluster randomized trial. Ann. Intern. Med. 2009, 151, 437-446. [CrossRef] [PubMed]

53. Cowling, B.J.; Zhou, Y.; Ip, D.K.; Leung, G.M.; Aiello, A.E. Face masks to prevent transmission of influenza virus: A systematic review. Epidemiol. Infect. 2010, 138, 449-456. [CrossRef]

54. Bin-Reza, F.; Lopez Chavarrias, V.; Nicoll, A.; Chamberland, M.E. The use of masks and respirators to prevent transmission of influenza: A systematic review of the scientific evidence. Influenza Other Respir. Viruses 2012, 6, 257-267. [CrossRef]

55. Ling, J.-X.; Wei, F.; Li, N.; Li, J.-L.; Chen, L.-J.; Liu, Y.-Y.; Luo, F.; Xiong, H.-R.; Hou, W.; Yang, Z.-Q. Amelioration of influenza virus-induced reactive oxygen species formation by epigallocatechin gallate derived from green tea. Acta Pharm. Sin. 2012, 33, 1533-1541. [CrossRef]

56. Hussain, M.; Galvin, H.D.; Haw, T.Y.; Nutsford, A.N.; Husain, M. Drug resistance in influenza A virus: The epidemiology and management. Infect. Drug Resist. 2017, 10, 121-134. [CrossRef]

57. Moher, D.; Liberati, A.; Tetzlaff, J.; Altman, D.G. Preferred reporting items for systematic reviews and meta-analyses: The PRISMA statement. BMJ 2009, 339, b2535. [CrossRef] [PubMed]

58. Rawangkan, A.; Kengkla, K.; Duangjai, A.; Saokaew, S. Anti- influenza with green tea catechins: A systematic review and metaanalysis. PROSPERO. 2020. Available online: https://www.crd.york.ac.uk/prospero/display_record.php?ID=CRD42020176371 (accessed on 11 June 2021).

59. Higgins, J.P.; Green, S. Cochrane Handbook for Systematic Reviews of Interventions; The Cochrane Collaboration: Melbourne, Australia, 2011.

60. Sterne, J.A.C.; Hernán, M.A.; Reeves, B.C.; Savović, J.; Berkman, N.D.; Viswanathan, M.; Henry, D.; Altman, D.G.; Ansari, M.T.; Boutron, I.; et al. ROBINS-I: A tool for assessing risk of bias in non-randomised studies of interventions. BMJ 2016, 355 , i4919. [CrossRef] [PubMed]

61. Wells, G.; Shea, B.; O'Connell, D.; Peterson, J.; Welch, V.; Losos, M.; Tugwell, P. The Newcastle-Ottawa Scale (NOS) for Assessing the Quality of Non-Randomized Studies in Meta-Analysis. 12 March 2020. Available online: http://www.ohri.ca/programs/ clinical_epidemiology / oxford.asp (accessed on 12 March 2021). 
62. Higgins, J.P.T.; Thompson, S.G.; Deeks, J.J.; Altman, D.G. Measuring inconsistency in meta-analyses. BMJ $2003,327,557$. [CrossRef] [PubMed]

63. DerSimonian, R.; Laird, N. Meta-analysis in clinical trials. Control Clin. Trials 1986, 7, 177-188. [CrossRef]

64. Borenstein, M.; Hedges, L.V.; Higgins, J.P.; Rothstein, H.R. A basic introduction to fixed-effect and random-effects models for meta-analysis. Res. Synth Methods 2010, 1, 97-111. [CrossRef]

65. Sterne, J.A.C.; Sutton, A.J.; Ioannidis, J.P.A.; Terrin, N.; Jones, D.R.; Lau, J.; Carpenter, J.; Rücker, G.; Harbord, R.M.; Schmid, C.H.; et al. Recommendations for examining and interpreting funnel plot asymmetry in meta-analyses of randomised controlled trials. BMJ 2011, 343, d4002. [CrossRef] [PubMed] 